Original Article

\title{
Effect of ankle-foot orthosis on weight bearing of chronic stroke patients performing various functional standing tasks
}

\author{
Kyoung Don Kim, MSc, PT ${ }^{1)}$, Hyun Jin Lee, MSc, OT ${ }^{2}$, Myoung Hyo Lee, PhD, PT $^{1)}$, \\ GaK Hwangbo, PhD, $\mathrm{PT}^{1)^{*}}$ \\ 1) Department of Physical Therapy, College of Rehabilitation Science, Daegu University: 201 \\ Daegudae-ro, Gyeongsan-si, Gyeongsangbuk-do 712-714, Republic of Korea \\ 2) Department of Occupational Therapy, Kyungwoon University, Republic of Korea
}

\begin{abstract}
Purpose] This study examined how an ankle-foot orthosis (AFO) influences the weight-bearing of chronic stroke patients during the performance of five functional standing tasks. [Subjects and Methods] Sixteen patients with stroke participated in this experiment. The subjects performed functional standing tasks with or without the AFO and weight bearing was measured during the tasks. [Results] Patients showed increased weight-bearing ability on the affected side during wearing the AFO in all tasks, and there were significant differences among Tasks 1,2 , and 3. Patients showed a small amount of increased weight bearing on the unaffected side while wearing the AFO in all tasks except for Task 2. [Conclusion] ADL-related functional standing tasks with AFO increased the weight bearing.

Key words: Ankle-foot orthosis, Weight bearing, Functional standing tasks
\end{abstract}

(This article was submitted Oct. 23, 2014, and was accepted Nov. 28, 2014)

\section{INTRODUCTION}

Weight-bearing ability has a major influence on the functional behavior of stroke patients ${ }^{1}$. The degree of weightbearing asymmetry while standing still is related to motor function in stroke patients, and the ability to shift weight in the forward and lateral directions is known to be highly related to walking ability ${ }^{2)}$. Cheng et al. reported that weightbearing asymmetry while rising from a chair increases the likelihood of falls in stroke patients ${ }^{3}$.

Strokes can manifest various clinical signs depending on the level and location of the cerebrovascular disease. One of the most common problems is a change in weight-bearing asymmetry during exercise or in a standing position ${ }^{4}$. The primary goal of functional rehabilitation for a patient with stroke-induced hemiplegia is to reduce the asymmetry of weight bearing ${ }^{5}$.

An ankle-foot orthosis (AFO) is generally used to improve a hemiplegic patient's weight transfer and gait. The AFO partially corrects abnormal gait such as foot drop during the swing phase, anteroposterior instability of the ankle and improper push off during the stance phase ${ }^{6}$. Moreover, it also supports and protects ankle joints, as well as correcting movements and helping fixation ${ }^{7}$. The AFO also increases

*Corresponding author. Gak Hwangbo (E-mail: hbgak@ daegu.ac.kr)

(C2015 The Society of Physical Therapy Science. Published by IPEC Inc. This is an open-access article distributed under the terms of the Creative Commons Attribution Non-Commercial No Derivatives (by-ncnd) License $<$ http://creativecommons.org/licenses/by-nc-nd/3.0/> . the body's weight-bearing on the affected side by improving the control ability of equinus or varus ankles, and reduces energy consumption while the wearer is walking ${ }^{8}$.

Eng and Chu evaluated weight bearing based on five functional standing tasks: rising from a chair, quiet standing, lateral weight shift, forward weight shift, and backward weight shift ${ }^{1)}$. The current study examined how an AFO influences the weight bearing of chronic stroke patients during the performance of these five functional standing tasks.

\section{SUBJECTS AND METHODS}

The subjects were 16 patients who had been diagnosed as having unilateral brain damage based on CT and MRI results. They were inpatients of F Hospital in Daegu between May and July 2014. The study subjects were chosen based on the following criteria: over six months since stroke onset; the patient had been prescribed an AFO by a rehabilitation medicine specialist; the patient had an MMSE-K score of 24 or over; the patient was able to stand up from a chair independently and had a Modified Ashworth Scale rating of 0 to while 1 using the AFO. The study excluded patients who were incapable of training, such as high-risk heart disease patients, patients with internal diseases, and patients with musculoskeletal disorders (Table 1). This study was approved by Daegu Fatima Hospital Institutional Review Board and consent was obtained from the subjects after the purpose of the study had been fully explained to them.

All of the study participants performed the five functional standing tasks suggested by Eng and Chu, and their weight bearing was measured on the affected side and on the unaffected side while they performed each of the 5 tasks ${ }^{1)}$. Each 
Table 1. General characteristics of subjects (mean \pm SD)

\begin{tabular}{lc}
\hline & Subject characteristics $(\mathrm{n}=16)$ \\
\hline Gender (M/F) & $5 / 11$ \\
Age (years) & $65.1 \pm 9.3$ \\
Affected side (Rt/Lt) & $9 / 7$ \\
Modified Ashworth Scale & G0: $10 / \mathrm{G} 1: 6$ \\
Time since stroke (months) & $9.9 \pm 1.9$ \\
Height $(\mathrm{cm})$ & $162.2 \pm 4.6$ \\
Weight $(\mathrm{kg})$ & $68.5 \pm 9.2$ \\
\hline
\end{tabular}

$* \mathrm{p}<0.05$

of the standing tasks was performed five times by each patient while wearing an AFO and five times while not wearing an AFO. In this study, the results of the first and last trials were excluded and the mean values of the results of the middle three trials were calculated.

The five functional standing tasks were: standing on both feet (task 1, rising from a chair; task 2, quiet standing) one foot (task 3, lateral weight shift; task 4, forward weight shift, and task 5, backward weight-shift). The location of the feet and the force measuring plates are shown in Fig. 1. Each task was performed using the following processes. In task 1 , weight bearing was measured at the time the buttocks detached from the chair. In task 2, weight bearing was measured while the patient maintained a comfortable standing position. In tasks 1 and 2, the subjects were asked to stand with their feet shoulder width apart. They were also asked to load their weight evenly on both feet and to maintain that stance for two seconds. In task 3 , the subjects were asked to stand with their feet shoulder width apart and place maximum weight on one foot. In task 4, the subjects were asked to put one foot in front of the other and place maximum weight on the front foot. They were then asked to place the heel of the front foot and the toes of the back foot on the same line and to maintain a width of one foot between the two feet. In task 5 , the subjects were asked to put one foot behind the other and place maximum weight on the back foot. Their posture during this stance was the same as for task 4 . When performing tasks 3,4 , and 5, they were asked to load their maximum weight on one foot while keeping the other foot on the ground and were asked to maintain that position for two seconds. They were then tested again using the opposite foot.

The patients performed all the tasks barefoot and the tasks were also performed randomly to eliminate learning effects.

Two force measuring plates (PDM-Multifunction Force Measuring Plate, zebris ${ }^{\circledR}$ Medical GmbH, Germany, 2004) were fixed firmly to the floor to measure the load on both lower limbs. One more plate was placed under the chair to detect the point at which the buttocks detached from the chair. The force plates measure static pressure and dynamic pressure using 1,504 pressure sensors, each one covering 1 $\mathrm{cm}^{2}$ on a $32 \times 47 \mathrm{~cm}$ plate. The force data was sampled at $600 \mathrm{~Hz}$.

In this study, the weight-bearing values were measured in Newtons and normalized by body weight to calculate the weight-bearing ratio. In the case of weight-bearing tasks using both feet (tasks 1 and 2), the measured value was divided

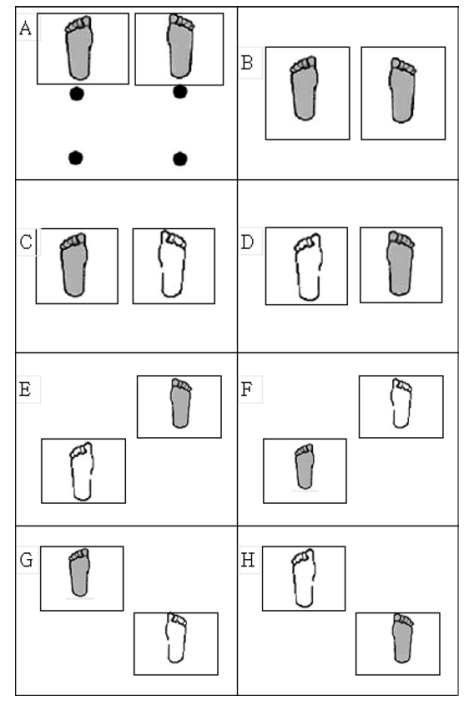

Fig. 1. Location of the feet and the force measuring plates during the standing tasks

A: rising from a chair; B: quiet standing; $\mathrm{C}$, D: weightshift laterally; E, G: weight-shift forward; F, H: weightshift backward

by half the patient's weight the body-weight ratio. In the case of weight-bearing tasks using one foot (tasks 3,4 , and 5), the measured value was divided by the patient's whole weight to calculate the body-weight ratio.

PASW 18.0 for Windows was used to analyze the results. The Mann-whitney test, which is a non-parametric test, was performed to compare the results of with and without an AFO of the affected and unaffected sides.

\section{RESULTS}

Patients showed increased weight-bearing ability on the affected side while wearing the AFO in all tasks, and significant differences $(\mathrm{p}<0.05)$ were found among tasks 1,2 , and 3 (Table 2). Patients showed a small amount of increased weight bearing on the unaffected side while wearing the AFO in all tasks except for Task 2. In Task 2, weight bearing significantly decreased (Table 3 ).

\section{DISCUSSION}

While a healthy person can maintain almost symmetric weight support when standing up or standing upright ${ }^{9)}$, this is very difficult for hemiplegic patients ${ }^{10}$.

When a hemiplegic patient performs the task of rising from a chair balanced weight bearing on both feet decreases the risk of fall ${ }^{3)}$. According to the results of this study, patients wearing an AFO on the affected side increased their weight bearing load from $78.67 \%$ to $100.83 \%$ while performing the task of rising from a chair. Cakar et al. reported that wearing an AFO improves a hemiplegic patient's rising from a chair task performance ${ }^{11)}$, which is in agreement with the results of this study, indicating that wearing an AFO reduces the asymmetry of weight bearing.

Eng and Chu reported that there is a lower weight-bearing ratio on the affected side compared to the unaffected side 
Table 2. Comparison of the tasks performed with and without an $\mathrm{AFO}$ in terms of the affected side (mean $\pm \mathrm{SD})$

\begin{tabular}{lccccc}
\hline Task & $\begin{array}{c}\text { Paretic limb } \\
\text { with non-AFO } \\
\text { (Newtons) }\end{array}$ & $\begin{array}{c}\text { Paretic limb } \\
\text { Normalized } \\
(\%)\end{array}$ & $\begin{array}{c}\text { Paretic limb } \\
\text { with AFO } \\
\text { (Newtons) }\end{array}$ & $\begin{array}{c}\text { Paretic limb } \\
\text { Normalized with } \\
\text { AFO (\%) }\end{array}$ & Difference \\
\hline Rising from a chair & $262.7 \pm 47.9$ & $78.6 \pm 12.4$ & $335.6 \pm 57.3$ & $100.8 \pm 16.4$ & $22^{*}$ \\
Quiet standing & $265.2 \pm 46.7$ & $79.9 \pm 14.2$ & $308.7 \pm 47.0$ & $92.1 \pm 8.4$ & $13^{*}$ \\
Weight-shift laterally & $465.0 \pm 105.0$ & $69.0 \pm 11.4$ & $553.7 \pm 83.6$ & $83.1 \pm 10.8$ & $14^{*}$ \\
Weight-shift forward & $399.3 \pm 207.0$ & $59.0 \pm 28.0$ & $430.5 \pm 195.7$ & $64.2 \pm 26.8$ & 5 \\
Weight-shift backward & $423.2 \pm 95.7$ & $63.2 \pm 12.6$ & $456.3 \pm 95.8$ & $68.4 \pm 13.0$ & 5 \\
\hline
\end{tabular}

${ }^{*} \mathrm{p}<0.05$

Table 3. Comparison of the tasks performed with and without an AFO in terms of the unaffected side (mean \pm SD)

\begin{tabular}{lccccc}
\hline Task & $\begin{array}{c}\text { Paretic limb } \\
\text { with non-AFO } \\
\text { (Newtons) }\end{array}$ & $\begin{array}{c}\text { Paretic limb } \\
\text { Normalized } \\
(\%)\end{array}$ & $\begin{array}{c}\text { Paretic limb } \\
\text { with AFO } \\
\text { (Newtons) }\end{array}$ & $\begin{array}{c}\text { Paretic limb } \\
\text { Normalized with } \\
\text { AFO (\%) }\end{array}$ & Difference \\
\hline Rising from a chair & $408.5 \pm 76.1$ & $121.3 \pm 12.4$ & $441.6 \pm 110.3$ & $131.3 \pm 24.2$ & 10 \\
Quiet standing & $406.0 \pm 88.8$ & $120.0 \pm 14.2$ & $368.7 \pm 70.4$ & $109.5 \pm 11.8$ & $-11^{*}$ \\
Weight-shift laterally & $575.1 \pm 112.8$ & $85.2 \pm 8.6$ & $576.5 \pm 88.4$ & $85.9 \pm 7.1$ & 0 \\
Weight-shift forward & $485.1 \pm 127.9$ & $72.5 \pm 17.0$ & $508.9 \pm 129.3$ & $76.3 \pm 17.5$ & 4 \\
Weight-shift backward & $514.5 \pm 118.1$ & $75.9 \pm 9.7$ & $530.4 \pm 110.9$ & $78.3 \pm 8.5$ & 3 \\
\hline
\end{tabular}

${ }^{*} \mathrm{p}<0.05$

when a hemiplegic patient performs the quiet standing task $^{1)}$. Many studies have reported that an AFO increases the weight-bearing ratio on the affected side in the static standing task ${ }^{4,8,12,13)}$. The results of the present study show that wearing an AFO increased the weight-bearing ratio on the affected side from $79.91 \%$ to $92.15 \%$ when the hemiplegic patients performed the quiet standing task, suggesting that an AFO improves static balancing ability.

Hemiplegic patients experience motor and sensory disability with abnormal body balance and asymmetric posture. In particular, they have difficulties with weight shifting and with the ability to transfer their weight in various directions ${ }^{12)}$. Some studies have reported that wearing an AFO improves gait speed and balance ${ }^{14,15}$. Sackey reported that improved weight-shifting ability correlates with improvements in gait ${ }^{2}$. Among weight-shifting tasks, Eng and Chu reported that transferring weight in a lateral direction is the easiest (due to the passive structure of the hip and knee, as well as the inherent stiffness of the trunk and SI joint), while transferring weight in a forward direction is the most difficult (as continuous muscle contraction and trunk motion control are required to maintain the knee joint) ${ }^{1)}$. The results of this study are similar to those of Eng and Chu. The weight-bearing values were largest in the order of lateral, backward, and forward directions. After wearing the AFO, the patients' weight-bearing ratios increased in all weightshifting tasks. Thus, it is clear that wearing an AFO allows hemiplegic patients to shift weight more easily in various directions thereby improv their gait ability.

This study had limitations with regard to the generalization of the results, as the number of subjects who met the selection criteria was relatively small. In future studies, it will be necessary to increase the number of subjects in order to assess the effect of an AFO on weight-bearing ability in acute and subacute stroke patients.

\section{REFERENCES}

1) Eng JJ, Chu KS: Reliability and comparison of weight-bearing ability during standing tasks for individuals with chronic stroke. Arch Phys Med Rehabil, 2002, 83: 1138-1144. [Medline] [CrossRef]

2) Sackley CM: The relationships between weight-bearing asymmetry after stroke, motor function and activities of daily living. Physiother Theory Pract, 1990, 6: 179-185. [CrossRef]

3) Cheng PT, Liaw MY, Wong MK, et al:: The sit-to-stand movement in stroke patients and its correlation with falling. Arch Phys Med Rehabil, 1998, 79: 1043-1046. [Medline] [CrossRef]

4) Kim TH, Gu AR, Kim JM: A study on the immediate effects of weight distribution and gait patterns of hemiplegic patients through PLS on and off. Korean Res Soc Phys Ther, 1996, 3: 55-76.

5) Wall JC, Turnbull GI: Gait asymmetries in residual hemiplegia. Arch Phys Med Rehabil, 1986, 67: 550-553. [Medline]

6) Lehmann JF: Biomechanics of ankle-foot orthoses: prescription and design. Arch Phys Med Rehabil, 1979, 60: 200-207. [Medline]

7) Licht S: Orthotics Etcetera. Am J Med Sci, 1966, 252: 158. [CrossRef]

8) Ferreira LA, Neto HP, Grecco LA, et al.: Effect of ankle-foot orthosis on gait velocity and cadence of stroke patients: a systematic review. J Phys Ther Sci, 2013, 25: 1503-1508. [Medline] [CrossRef]

9) Engardt M: Rising and sitting down in stroke patients. Auditory feedback and dynamic strength training to enhance symmetrical body weight distribution. Scand J Rehabil Med Suppl, 1994, 31: 1-57. [Medline]

10) Alexander NB, Schultz AB, Warwick DN: Rising from a chair: effects of age and functional ability on performance biomechanics. J Gerontol, 1991, 46: M91-M98. [Medline] [CrossRef]

11) Cakar E, Durmus O, Tekin L, et al.: The ankle-foot orthosis improves balance and reduces fall risk of chronic spastic hemiparetic patients. Eur J Phys Rehabil Med, 2010, 46: 363-368. [Medline]

12) Lim HY, Chang IS, Bang YS, et al.: A study on effect in hemiplegic patients in the hinged plastic ankle foot orthosis and solid plastic ankle foot orthosis. J Korean Soc Phys Ther, 2004, 16: 507-520.

13) Kim JH, Kim CS: Effects of plastic AFO and shoes on static standing balance in hemiplegic patients. J Korean Soc Phys Ther, 2001, 13: 381-397.

14) Gök H, Küçükdeveci A, Altinkaynak H, et al.: Effects of ankle-foot orthoses on hemiparetic gait. Clin Rehabil, 2003, 17: 137-139. [Medline] [CrossRef]

15) Mauritz KH: Gait training in hemiplegia. Eur J Neurol, 2002, 9: 23-29, 53-61. [Medline] [CrossRef] 